\title{
Tempo de travessia, tempo de recriação: os camponeses na caminhada
}

BERNADETE CASTRO OLIVEIRA

“Todas as coisas têm o seu tempo e todas elas passam debaixo do céu segundo o tempo a que cada uma foi prescrito. Há tempo de nascer e tempo de morrer. Há tempo de plantar. Há tempo de arrancar o que se plantou..."

(Eclesiástes; 3-1)

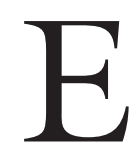

NQUANTO movimento social, a luta camponesa tem demonstrado, ainda que em pequena escala, a forma dinâmica das estruturas sociais, onde os sistemas de hierarquia e ordem são reativados no momento do conflito e contribuem para estabelecer um objetivo comum. Instaura-se um momento de ruptura das relações estabelecidas no interior de um grupo (ou de vários grupos), que podem assumir características diversas daquelas estruturadas em período de normalidade, adquirindo uma outra lógica que se põe pela necessidade de sobrevivência ou enfrentamento.

O movimento camponês pressupõe um estado de contestação. Os ideais e as práticas contestantes são relevantes à medida em que constituem uma interpretação divergente da ordem estabelecida, ou do "novo" que desestrutura as relações sociais existentes. São comportamentos incorporados pelos indivíduos como forma de resistência, podendo se desdobrar em movimentos mais amplos, criando novas condutas que pressupõem linguagem, rituais e práticas inovadoras (muitas vezes no sentido de reinvenção), elaborando um referencial utópico no qual se protegem do presente e se inserem no futuro.

As comunidades remanescentes de quilombo no Vale do Ribeira talvez sejam um bom exemplo. Sua luta pela terra validando o direito de posse, revestiu-se como uma luta de caráter étnico pelo reconhecimento da descendência das populações negras que povoaram aquelas áreas desde o século XVII, revelando assim uma forma de apropriação da terra que foge à lógica mercantil da compra e venda.

Woortmann (1997: 80) assinala "que o parentesco legitima e codifica a propriedade no plano das regras ideais, associando a ele valores, como característica 
permanente da cultura e, se é preciso 'inventar' uma ancestralidade, não estaria expressando uma rejeição ideológica da aquisição da terra por compra?”

O direito de posse aparece tendo como substrato uma terra que se define e se constitui a partir da morada e cultivo. A morada (casa-domicílio-família) é a base da organização do trabalho e da produção, e efetiva através dela, o direito à terra. Tanto que no caso da conquista da terra o marco primeiro das ocupações feitas pelo MST é o "barraco", com a família, para transfigurar a "terra de negócio" em "terra de morada" .

Nesse sentido, a terra de cultivo e morada se opõe às relações de mercado enquanto estrutura básica, oferecendo resistência à lógica capitalista da acumulação. Tal aspecto não significa que, enquanto unidade de produção/consumo, esteja alheia às trocas mercantis, mas que as desenvolve a partir das necessidades e perspectivas do grupo doméstico.

Mediante essa negação do valor de mercado, mostra a existência de uma racionalidade que se estabelece a partir de uma sociabilidade, de um direito, de uma moral, que negam princípios capitalistas de produtividade e de rentabilidade que valorizam o capital. Ao contrário, o cálculo econômico no sentido de um empreendimento familiar busca a valorização do trabalho como categoria estrutural das relações de produção.

Decorrente disso, os termos que definem uma agricultura camponesa têm de ser discutidos não a partir de uma economia de mercado, como normalmente é feito, mas buscando-se sua definição a partir de características específicas no interior dessas unidades, algo que se situa mais na esfera da autonomia da produção do que na dependência da circulação. Unidades que se diferenciam, no tempo e no espaço, de leis gerais de relações de produção determinantes ou globais, muitas vezes como produtos antitéticos do desenvolvimento geral da sociedade.

De modo geral, na concepção camponesa há sempre referências à terra como dom, da natureza ou de Deus. Essas referências estão sempre ligadas à idéia de direito (direito deles sobre a terra), como "a terra é de Deus; ... a terra, foi Deus quem fez."

Aparecido Galdino, no oeste paulista dos anos 60, quando se referia ao direito que o povo tem à terra, afirmava que o "Reino de Deus é o reino desse mundo" e "... aquele que permaneceu na terra, amou seu irmão, ele herda o Reino de Deus". Dentro dessas concepções há, do mesmo modo, implícita a regra de que os filhos herdam o que é do pai; há uma "descendência simbólica" que sela esse direito à terra, expressa por laços de uma "sagrada família" - são todos filhos de um mesmo Pai, portanto, todos irmãos que devem compartilhar a herança.

Podendo talvez melhor esclarecer algumas colocações anteriores - aproveitando a reconstituição etmológica do termo cultus feita por Bosi (1994) em 
sua Dialética da Colonização como “adjetivo deverbal”, como atribuição feita ao campo que já fora arroteado por gerações sucessivas de lavradores, a terra que se lavrou (ager cultus, lavra, roçado) - há um sentido cumulativo na experiência que indica processo (a sociedade que assim procede guarda a experiência, tem memória). Por outro lado, cultus, como substantivo, "queria dizer não só o trato da terra, mas também o culto aos mortos", chamamento ou lembrança. Desse modo, culto e cultivo estão embutidos numa dimensão sagrada.

Dentro de regras do direito costumeiro, as práticas sociais permitiram a apropriação de matas, águas e terras, mostrando uma legitimidade que é expressa numa jurisprudência camponesa, na qual podemos identificar dois eixos sempre presentes que orientam tais práticas: os laços de descendência e os laços de territorialidade, constituindo-se sob formas como: terra de remanescentes de quilombos, reserva extrativista, terra de santo, terra no comum etc.

Vários dos grupos que hoje discutem um projeto político no qual possam se colocar, buscam restabelecer a unidade grupal, muitas vezes num plano simbólico, o que lhes permitiria ordenar as práticas dos indivíduos perante o enfrentamento com a sociedade, revelando uma nova coesão dada a partir de uma situação de conflito. Esse simbolismo, que fundamenta a luta, é preenchido num sistema de crenças rico em sincretismos, próprio de nossa cultura.

Wolf (1974), reafirma a importância de serem estudadas as populações camponesas dotadas de um respeito profundo pela força da tradição, e que tanto a persistência quanto a mudança são pontos de indagação antropológica. As rebeliões camponesas do século XX são interpretadas não como problemas locais, mas reações às mudanças sociais mais amplas. A expansão do mercado, a industrialização, instauraram novas posições e interesses, consolidado novos grupos. A autoridade política tradicional foi abalada e instaurado um novo contexto social, econômico e cultural. A sublevação camponesa não se dá apenas por terra e liberdade, ela tenta impor uma nova ordem, um mundo da justiça - um Mundo Novo.

Shanin (1979), analisando a mudança, mostrou que quando o mundo camponês é ameaçado pela sociedade mais ampla, o que está realmente em jogo é a sua própria existência.

A perda da área de lavoura e da morada efetiva traduz sempre um movimento reivindicativo que põe o camponês em confronto com a sociedade. Ele passa a estabelecer diferenças entre passado e presente, demonstrando o confronto entre duas ordens: uma tradicional, baseada na reciprocidade, costumes e posse da morada; outra moderna, ditada pelo trabalho assalariado e perda da morada.

Esse dilema é encontrado em grande parte da população engajada nos movimentos no campo do Brasil atual, os brasiguaios por exemplo. Retornados para a fronteira brasileira na região de Foz do Iguaçu, eles procuram resgatar valores da vida camponesa dentro dos acampamentos. 
As transformações econômicas pressupõem que os agentes sociais elaborem uma consciência da privação. Assim, os camponeses se vêem entre duas vertentes impostas pelas mudanças: de um lado a expulsão e a morte; do outro, a terra e a vida. Talvez por isso, antevejam sempre a salvação prescrita na "terra prometida".

No caso daqueles que não possuem a terra e têm de conquistá-la, estão em jogo as condições físicas de existência, além de uma luta ideológica e moral que devem travar contra a sociedade, como o faz o Movimento Sem-Terra. Aos integrantes organizados pelo movimento é atribuído um comportamento desviante, perigoso nas caminhadas e ocupações, que deve ser combatido, por se traduzir em baderna e desordem social.

A situação de conflito impõe uma guerra da sociedade contra os valores e comportamentos tradicionais, uma vez que a relação de dominação imposta pelos agentes do "mundo moderno" leva os camponeses a uma condição de "degradação moral”.

Na maioria das vezes, a mídia no Brasil tem se prestado a destituir de validade as reivindicações de grupos organizados, como ocorreu com o Movimento dos Atingidos por Barragens, o Movimento dos Pequenos Agricultores, o MST, e mesmo as representações indígenas, geralmente mostrados como retrógrados, sujeitos sociais num patamar inferior, "estranhas classes" de pessoas, cuja civilidade ainda está por se fazer.

Num jogo de futebol entre jovens de um assentamento do MST e o time de uma cidade do interior de São Paulo, ao término da partida, os jovens da cidade dirigiram-se aos assentados dizendo: "No começo ficamos com medo, mas depois vimos que vocês falam bem e também são limpos...". A noção de sujeira/ limpeza é uma construção cultural e, nesse caso, a "sujeira" é ideológica - um quesito de discriminação para menos e para baixo, dentro de uma visão de classe.

Tal aspecto, é muito bem abordado por Bailey (1979: 272) em antigo estudo sobre camponeses indianos: "... las sugerencias o las órdenes para que se asuman papeles moderno, politicos o económicos, provienen de la comunidad moral exterior: en consecuencia, automáticamente se definen como peligrosas y pecaminosas, y los aldeanos que adopten los nuevos papeles corren el viesgo de ser marcados como descarnados y castigado".

Como as formas de controle e poder são amplamente disseminadas, tornando-se repressoras, preenchendo a vida dos indivíduos e obrigando-os a reinventarem no dia a dia estratégias oponentes, o conflito é latente dentro da vida social. A luta por terra e trabalho assume o caráter político e se inscreve nele. Essa reelaboracão cotidiana é sentida e experimentada nas práticas dos sujeitos enquanto experiências de diferenciação e/ou oposição, gerando contestações de diversos graus e natureza. Tensões internas surgem nos movimentos e exigem de 
seus membros reflexões que, ao serem feitas, geram uma pedagogia interna para a consecução de seus objetivos e criação de seus quadros.

A educação, as relações étnicas mesmo as relações de gênero passaram a ser priorizadas dentro dos assentamentos e acampamentos e passaram a compor uma pauta muito importante nas organizações no campo, dando origem ao Movimento das Mulheres Agricultoras em Santa Catarina e no Paraná, que adotam a luta pela terra na sua construção diferenciada pelas relações de gênero.

Há mais de uma problemática posta pelo desenvolvimento da sociedade mais ampla à uma sociedade camponesa que não se reproduz em nível da pura e simples reprodução capitalista, mas engendra contradição entre o modo de vida camponês e o capital. Contradições internas ao mundo camponês, que ora propõem a estes produzir acima de suas necessidades e se engajarem ao mercado, ora propõem reduzir seu consumo ou sua produção, para resistirem às situações hostis impostas pelo mercado.

Por isso, a retomada dos slogans dos movimentos no campo (e também urbanos) é marcada por forte oposição às políticas neoliberais que condicionam os projetos e financiamentos para a agricultura, no Brasil e em vários países da América Latina.

Essas mudanças ocorridas nas relações entre os camponeses e a sociedade, o Estado ou mesmo o mercado, alteram seus vínculos com a terra. Os conteúdos étnicos, a preservação ambiental, o novo espaço dos assentamentos, exigem redefinir os laços com a terra, uma nova territorialidade. Inspiram também um novo pertencimento, no qual ser camponês não é apenas "estar dentro" de um projeto ou movimento, mas voltar-se para fora. Retoma-se aqui a Bloch (Münster, 1997), ao trabalhar a "redefinição do conceito ser como modo de possibilidade para frente".

As migrações e as formas de resistência camponesa têm aparecido como importantes agentes do processo político do campesinato no Brasil, envolvendo as tradições culturais mantidas na memória camponesa, permitindo recuperar aspectos míticos e místicos traduzidos em profecias e profetas, líderes e mártires, cujo culto passa a ser ressignificado pelos movimentos. Essa imaginação traz articuladas política e religião, mobilizando elementos fundamentais na luta camponesa - terra, trabalho e crenças.

Não seria sem propósito recuperar o modo pelo qual Ernst Bloch é retomado por Münster (1997) ao tratar das lutas camponesas e apontar para a "teoria das forças religiosas e misticas que impulsionam a consciência revolucionária". As heresias aparecem como comportamento contestante dentro das doutrinas religiosas. O mundo católico as reconheceu na Europa com Joaquim de Fiore, Thomas Münzer, entre outros. As idéias heréticas são relevantes à medida em que constituem uma interpretação divergente das doutrinas, e em que são adotadas 
pelos indivíduos como resistência e contestação, podendo se expandir em movimentos maiores, transformando o comportamento contestante em uma nova conduta (linguagem, ritual, práticas).

Tanto os movimentos milenaristas quanto os messiânicos são, em grande parte, segundo uma valoração negativa, grupos sociais em processo de transformação econômico/cultural fadados à decadência. Consideram-se nessa perspectiva as mudanças culturais trazidas pela colonização e, depois, pelos agentes da modernização aos países em desenvolvimento. Isso leva a uma visão evolucionista da formação social, na qual as formas associativas grupais, cujas relações são tradicionais ou pré-políticas, se transformariam em relações políticas modernas, secularizadas, (ecológicas e até virtuais), condicionando uma avaliação equivocada sobre as atuais organizações no campo brasileiro.

Nesse sentido, os movimentos religiosos com grande carga simbólica relacionada ao sagrado e os movimentos revolucionários de caráter secular seriam excludentes. Assim, a ação revolucionária é concebida como algo monolítico, que só se faz mediante um projeto global de transformação da sociedade.

As condições em que eclodem os movimentos sociais dependem do grau de diferenciação da sociedade, das relações de poder, do grau de organização das forças produtivas, das esferas políticas, religiosas e culturais. Elas definem as possibilidades que o grupo tem de alcançar os fins propostos, mostrando-se mais restritas ou abrangentes segundo tais determinações. As condições de elaboração de um projeto político dependem também da relação que o grupo mantém com a sociedade envolvente, e da maior ou menor integração com os sistemas de reprodução do poder, podendo estabelecer, de acordo com seus meios de ação, um questionamento radical ou parcial da sociedade, cujos exemplos a América Latina tem oferecido fartamente.

Qualquer que seja o caso, a negação do status quo verifica-se de modo a localizar os grupos contestantes numa esfera de relativa autonomia com relação à ideologia dominante, ocupando interstícios da estrutura social e aparecendo como grupos liminares. Esse processo de exclusão alimenta estratégias de sobrevivência e resistência que, na maioria das vezes, resulta numa contra-cultura portadora de novos elementos simbólicos e novas condutas que precisam ser interpretados.

Essas ações criam condições para se pensar de que modo a concepção de mundo de setores do campesinato questiona e resiste à noção de progresso imposta pela sociedade industrial. Nessa visão, o progresso em seus aspectos qualitativo e quantitativo evidencia um certo grau de desenvolvimento das relações entre os homens e a natureza, e dos homens entre si, condição que permite a formulação de projetos mais amplos (talvez como a preservação ambiental).

A formulação de outros tantos projetos, que muitas vezes se encontram em posição subalterna nas relações da vida material e em posição antagônica na esfe- 
ra das representações, é assim inibida. Podem apontar para uma outra forma de consciência, ainda que estruturada segundo princípios inscritos nas tradições, no caso, na Grande Tradição (judaíco-cristã).

Esse caminhar constante que está no ideário camponês de buscar o novo, descreve sempre a superação do presente como missão. Por isso, em vários momentos, quando as transformações sociais e econômicas provocam crises no interior da vida desses grupos, torna-se iminente o surgimento de um líder capaz de traduzir as angústias e as esperanças na possibilidade de um mundo novo - uma nova geração no caso do messianismo; ou de lideranças que articulem esse novo momento à construção da reforma agrária.

No mundo capitalista, a expansão econômica objetivando o lucro e a mediação da mercadoria nas relações sociais elaboram padrões que garantem a reprodução das relações de produção que, de um lado, impõem o controle e a dominação, mas de outro não cobrem recriações (práticas) dos sujeitos ou manifestações que tomam a forma de estagnações ou "retrocessos", e que se apresentam como resistências ao progresso social.

É nesse momento, que aparece como ruptura, no qual os grupos sociais numa situação de exclusão elaboram um universo de valores contestantes da ordem social, surgem como "segregadores e subversivos". Muitas vezes esses grupos buscam, numa linguagem mítica ou utópica, a explicação de sua situação cotidiana, restabelecendo no plano do sagrado ou do devir, a condição social que lhes é negada no plano econômico e político presentes.

No momento de crise, as representações elaboradas pelo grupo evidenciam maneiras de agir e pensar compatíveis com o contexto de sua existência. A criação de um espaço simbólico permite o reconhecimento da legitimidade e da identidade social por parte daqueles que, numa posição subalterna, tentam reafirmar valores e regras de um modo de vida, opondo-se a outro.

Esse antagonismo reflete uma conjuntura por meio da qual se expressam setores de classes diferenciados, exigindo repensá-la não como um conjunto monolítico de sujeitos em oposição a uma outra classe dominante, mas permitindo compreender níveis diversos em que a contradição se dá na sociedade e entre sujeitos através de níveis de dominação, de apropriação dos bens materiais e simbólicos, criando formas de resistência diversificadas.

A situação de migração implica uma complexidade de interesses entre os novos sujeitos que passam a compor esses espaços nas novas áreas. Os conflitos gerados pela desigualdade da posse de bens produzem também conflitos de significados, exigindo desses sujeitos novas posturas diante do mundo e das coisas, estranhamentos e resistências.

Essas resistências manifestam-se em várias esferas da vida desses grupos camponeses, reconstruindo relações dentro de novos códigos, linguagens e re- 
presentações. As relações da família, do trabalho familiar, das práticas religiosas e das festas reinscrevem-se num universo novo, que mistura a memória com as novas práticas, passado com o presente.

O contato cultural entre segmentos diferentes da sociedade brasileira processou-se historicamente nas áreas de migração, acampamentos e assentamentos, provocando desarticulações e reconstituição de modos de vida, exigindo desses grupos estratégias de sobrevivência.

Se por um lado criam mecanismos de enfrentamento com a sociedade envolvente, por outro desenvolvem mecanismos internos que permitem manter uma certa identidade enquanto grupos que nem sempre são opostos entre si, pois também se criam entre muitos deles relações de reciprocidade, diminuindo distâncias sociais, aproximando modos de vida.

Os movimentos são bastante complexos por trazerem em si tradicionalismo e contestação. Sua extensão ou duração inscreve-se no âmbito das necessidades impostas pelo grupo, e de sua realização dentro do contexto social no qual ocorrem.

É como se os camponeses continuamente tivessem de enfrentar a tragédia das mudanças, vendo tudo se fechando ao seu redor, tendo de descobrir o caminho para passar para o outro lado e reconstruir a vida. Essa travessia, experimentada por tantos grupos camponeses na história brasileira, se traduz na busca, num caminho que está quase sempre no horizonte, onde terra e céu se encontram, e muitas vezes não se separam, nos olhos daqueles que vêem e que crêem.

O rito e o culto aparecem nos movimentos preenchendo e ordenando simbolicamente os espaços por onde transitam seus atores. Essa interpretação permeou a participação da Igreja nos movimentos no campo e chegou aos movimentos como o MST, o MPA, remanescentes de quilombos. É uma simbologia que sacraliza o discurso costurando ideologias e mitos, colocando lado a lado Antonio Conselheiro, Zumbi, Che Guevara, Florestan Fernades, Darcy Ribeiro, Roseli Nunes, entre outros.

A mística trabalhada no interior do MST, e que hoje é partilhada por outros grupos, representa um "ritual de acolhida" e mais, "uma matriz de formação" para exercício e continuidade da luta, como descreve Caldart (2000) ao mencionar a pedagogia do MST.

As ações embutidas numa prática ritual abrem espaço para pensar uma outra lógica, uma outra concepção de mundo, pela qual setores do campesinato questionam e resistem à noção de desenvolvimento social imposta pela sociedade tecnológica/financeira. Nesse enfoque, o desenvolvimento, em seu aspecto quantitativo, evidencia um grau, uma posição na qual os camponeses e demais camadas pobres não se inscrevem. 
$\mathrm{Na}$ literatura antropológica essas questões aparecem em vários estudos, evidenciando processos sociais que caracterizam momentos de transformação pelos quais passam os diferentes grupos sociais. São mudanças que levam não só à transformação da vida material, mas à necessidade de buscarem, quase sempre, uma resignificação simbólica para sua existência.

As transformações históricas levaram as sociedades camponesas a um processo de mudança que interferiu não só em sua estrutura familiar, mas também em sua organização econômica, pois tiveram de se colocar dentro de uma nova ordem de relações impostas pela sociedade capitalista, recirando-se.

Diante da escassez de recursos técnicos e de linhas crédito, essa população de assentados ou pequenos proprietários é obrigada a criar estratégias de sobrevivência e alternativas que possibilitem implementar a unidade produtiva dentro de uma autonomia camponesa desassistida pelas políticas agrícolas.

Faz parte de um conhecimento propriamente camponês, dinâmico e autônomo a apreensão e a classificação da natureza e das coisas, possibilitando o desenvolvimento de técnicas de cultivo que permitem, por exemplo, aproveitar a sazonalidade no semi-árido alagoano - os camponeses que moram na chapada e plantam na caatinga após as chuvas, as roças de milho e feijão - Associação dos Agricultores Alternativos (AAGRA).

Outro exemplo desse conhecimento é a seleção de sementes dos pequenos produtores do MPA de São Mateus, no sul do Paraná - mais de 50 tipos de espécies de milho e feijão são selecionadas e trocadas nas feiras de sementes.

Diante desse mundo em transformação, o campesinato tem de ser entendido em seus aspectos internos e externos, e na diversidade de suas formas de existência, para que se possa dar conta do significado de sua prática social e de sua linguagem do ponto de vista cognoscente.

Enquanto fenômeno social, o campesinato é abordado sob enfoques teórico-metodológicos que se contrapõem, como bem apontou Geertz (1978), polarizando visões marxistas e não-marxistas quanto à análise de classe e sociedade, levando a dicotomias conceituais ainda presentes em muitas análises: "la hermandad frente a la competencia económica de Maine; lo familista frente a lo individualista de De Coulangue; la Gemeinschaft frente a la Gesselchaft de Tönnies; o las sociedades mecánicas (segmentadas) frente a las orgánicas de Durkheim..." (Shanin, 1979).

É como se a dicotomia conceitual resolvesse, por meio de um sistema classificatório, a dinâmica das categorias sociais, pela qual o camponês dá lugar ao agricultor, ao pequeno produtor e, hoje, ao produtor familiar. Coisa que o camponês sempre foi; mas quando não se consegue compreender essa categoria em novos contextos, muda-se a sua definição para servir às estatísticas. 
Torna-se necessário, portanto, uma concepção dinâmica das sociedades, quaisquer que sejam elas, tendo em vista que as transformações surgidas pelo desenvolvimento histórico põem em movimento tanto seus aspectos formais (aparentes) quanto seu conteúdo, que nem sempre guardam entre si uma relação de correspondência direta.

A estratificação social colocada por Balandier (1987), relaciona-se a "sistemas de desigualdade e dominação", cujo conflito é inerente à constituição dos segmentos sociais. Os movimentos sociais requerem a existência de grupos diferenciados na estrutura social, que não apenas expressam uma dimensão geral da sociedade na qual estão inseridos, mas expressam essa realidade sob a forma do vivido - o que não afasta formulações de caráter ideológico.

Esses movimentos são dotados de conteúdo ideológico, de modo que as crenças ou doutrinas refletem a situação dos setores sociais que formam sua base. Em outras palavras, tomam como preceitos aqueles que parecem justos e adequados a um setor determinado da sociedade para servir como paradigma de experiências.

A interpretação sobre as sociedades e as culturas não deve ser feita apenas a partir das determinações gerais impostas pelo processo histórico no sentido de formas sucessórias, tomando como base os elementos determinantes de uma forma mais elaborada que se coloca como grau mais elevado desse desenvolvimento, mas considerar as descontinuidades decorrentes desse processo, que se contrapõe à linearidade e à homogeneidade do desenvolvimento. Os grupos sociais, as práticas e o próprio conhecimento aparecem como elementos dinâmicos e complexos a fim de exprimir o caráter contraditório e heterogêneo do movimento da história.

A luta pela terra que o campesinato tem deflagrado é uma luta pela sua recriação. Recriação, porque se dá mediante processos não-lineares dentro de sua reconstituição histórica, ou seja, atravessa descontinuidades. Esta é uma categoria social constitutiva de várias sociedades, e a "estranha classe" constitutiva do capitalismo. Traz em si um tempo próprio de existência, dado pelas lógicas internas que estruturam seu modo de vida, da mesma maneira que responde de formas variadas à lógica social mais amplo. É como se o campesinato vivesse dentro de um processo constante de morte e ressurreição e, nesse movimento, conseguisse descrever a sua trajetória de sujeito histórico.

\section{Referências bibliográficas}

BAILEY, F.G. La visión campesina da la vida mala. In: SHANIN, T. Campesinos $\Upsilon$ sociedades campesinas. México, Fondo de Cultura Económica, 1979.

BALANDIER, G. Antropólicas. São Paulo, Cultrix/USP, 1987. 
BALANDIER, G. Le detour. Pouvoir et modernité. Paris, Fayard, 1985.

BOSI, A. Dialética da colonização. São Paulo, Cia. das Letras, 1994.

CALDART, R.S. Pedagogia do Movimento Sem Terra. Petrópolis, Vozes, 2000.

CÂNDIDO, A. Os parceiros do Rio Bonito. São Paulo, Duas Cidades, 1975.

CHAYANOV, A.V. La organización de la Unidad Económica Campesina. Buenos Aires, Nueva Visión, 1974.

DELUMEAU, J. Mil anos de felicidade: uma história do Paraíso. São Paulo, Cia. das Letras, 1997.

GEERTZ, G. A interpretação das culturas. Rio de Janeiro, Zahar, 1978.

HIGASHI, L.H.M. Crise e ressurreição. São Paulo, 1995. Dissertação (mestrado), Departamento de Sociologia, FFLCH-USP.

LEFEbVRE, H. La velleé de Campan: étude de sociologie rurale. Paris, PUF, 1963.

MARTINS, J.S. Caminhando no chão da noite: emancipação política e libertação nos movimentos sociais no campo. São Paulo, Hucitec, 1989.

MONTEIRO, D.T. Os errantes do novo século: um estudo sobre o mito milenarista do Contestado. São Paulo, Duas Cidades, 1974.

MÜNSTER, A. Utopia, messianismo e apocalipse nas primeiras obras de Ernst Bloch. São Paulo, Ed. Unesp, 1997.

SAHLINS, M. A primeira sociedade da afluência. In: CARVALHO, E.A. Antropologia Econômica. São Paulo, Livraria Ciências Humanas, 1978.

SHANIN, T. Campesinos y sociedades campesinas. México, Fondo de Cultura Económica, 1979.

WOLF, E. La paysannerie e ses problèmes. In: Un domaine contesté: l'anthropologie économique, Paris, Godelier, M. Moutun Éditeur, 1974.

WOORTMANN, K. \& WOORTMANN, E. O trabalho da terra. Brasília, Ed. UnB, 1997.

Bernadete Castro Oliveira é professora de Antropologia no Departamento de Planejamento Territorial e Geoprocessamento do Instituto de Geociências da Unesp, campus de Rio Claro. 